\title{
Sustainable Agriculture on the Internet: Practical Uses
}

Jill Shore Auburn ${ }^{1}$

Summary. The Internet has experienced tremendous growth recently. The number of users, the amount and diversity of information available, and exposure in the mass media have all grown rapidly. Several authors recently have asserted that the media reports are overblown and that Internet is not as useful as most reports portray. Agricultural professionals need to assess whether or not the cost of using the I nternet (in learning time as well as money) will benefit them in terms of increased knowledge and productivity. This paper describes current use of the Internet to answer practical questions from research and education, using a survey and practical examples from sustainable agriculture.

Additional index words. electronic mail, World Wide Web, survey

T he system of interconnected computer networks known as the Internet has experienced remarkable growth recently. Although it is difficult to estimate precisely the number of users (Crawford, 1995), one authoritative source estimated 27.5 million users of electronic mail in O ctober 1995 (MIDS, 1995) and about $100 \%$ annual growth in Internet hosts (Q uarterman and Phillips, 1993). The diversity of users has expanded as well, from primarily university and government users to the private sector, and to the general public through linkages to commercial providers such as American O nline, Compuserve, and others. The amount of information available on the Internet, and the power and user-friendliness of the tools used to access it, such as the hypertext/ multimedia World Wide Web (WWW), have exploded similarly. General interest magazines and newspapers routinely list I nternet addresses and uniform resource locators (URLs), such as http:/ / www.sarep.ucdavis.edu/ for the author's program's WWW home page) in articles and advertisements.

This explosion in attention has stimulated questions and critiques. In the words of Finn (1995), the Internet to some may be a supercollider rather than a superhighway, akin to a vast library with a badly organized card catalog. 
Stoll (1995) provided an engaging critique of the Internet, full of cautionary examples of its shortcomings from his longstanding experience with that medium. Dennett (1994) observed that the Internet can be interesting and useful, but is weak in tools and organization, so that posting a question to a mail group may be more efficient than searching for an answer through archives of previous postings to mail groups or other Internet databases. Pagell (1995) observed that most of those who ask and answer questions on many library/ information science "listservs" (electronic mail groups) appear to be new to the profession and not professionally trained. She finds most questions naive, questions the authority of those responding, and suggests that readers "try the art of reading" to discover more authoritative and carefully documented answers to their questions in the professional literature. 0 thers agree that the Internet is oversold, particularly for commercial applications (J ennings, 1995; N ulty, 1995; R othke, 1994; van Kirk, 1994).

$M$ any agricultural researchers at universities have convenient and often free (to the individual) access to the Internet and to technical support and training. For them, the primary personal cost of using the technology is the time to learn and use it. Private-sector professionals, as well as many university professionals located off-campus (e.g., field station personnel and cooperative extension agents) often facegreater obstaclesand costs. Their willingness to overcomethese obstacles and costs will depend on the perceived and real value of the I nternet in finding answersto day-to-day, practical questions that arise on the job, as well as providing useful and interesting background information that enhances the professional's overall knowledge base. It may also depend on acceptance by clientele. Since there is evidence ( $L$ andauer, 1995) that computer applications generally have contributed little to real productivity enhancement in A merican industries ( particularly service industries, including those that are considered knowledge-intensive), ahealthyskep- ticism would seem warranted. The purpose of this paper is to explore practical use of the Internet in answering real-life agricultural questions to help agricultural professionals make the most effective use of the Internet. Examples are taken mostly from sustainable agriculture databases and resources, particularly those sponsored by the Sustainable Agriculture $\mathrm{N}$ etwork (Auburn and $\mathrm{M}$ acL ean, 1993). Sustainable agriculture is often referred to as the intersection of three types of goals: economic, environmental, and social (D ouglass, 1984; G ips, 1988). N arrower definitions emphasizing environmentally sound and profitable production and ignoring or de-emphasizing human and communitygoals arealso common, particularly among agronomists and horticulturists (Fretz et al., 1993; $\mathrm{H}$ arwood, 1990; Keeney, 1990).

\section{Sustainable Agriculture Network's Internet resources}

The Sustainable Agriculture N etwork (SAN) started in 1991 at the request of the U SD A'snational SustainableAgriculture Research and Education (SARE) program, to facilitate sharing of information from SAREsponsored research and other sources. SAN has produced a number of publications and databases that are distributed simultaneously in print and electronic forms. SAN resources include a showcase of educational materials (SAN , 1994), a directory of individuals and organizationswith sustainableagricultureexpertise (SAN , 1993a), a database of summaries of research projects funded by SARE (SAN , 1993b), and a series of handbooks on practical topics, beginning with cover crops (SAN , 1992). All of these materialsare searchable on the Internet via gopher (gopher.ces.ncsu.edu) and viaWWW (http:/ / www.ces.ncsu.edu/san/). SAN also supports an electronic mail discussion group, Sanet-mg (subscription information is available from the SAN coordinator, san@nalusda.gov), which had about 750 subscribers as of February 1996, plus an indeterminate number who participate via U senet's alt.sustainable.agriculture.

SAN's resources are intended to be complementary to one another and to other agricultural resources availablein print and on the Internet. In searching for the answer to a practical question, a user might consult first the handbook series (if ahandbook is available on the topic in question) for a practical discussion of information summarized
Responses (no.)

3

9

18

26

8

2 
from a variety of sources or look for another practical publication in the showcase of educational materials. A morein-depth (but probably lessgeneral) answer might be availablein the SARE research projects database (or in another general database of current agricultural research projects such as the USDA research database on WWW at http:/ / medoc.gdb.org/ best/ stc/ usda-best.html). If those databases fail to yield a satisfactory answer or contact, an individual with related experience or knowledge might be found in theSAN directory of expertiseand/ or through a query to the Sanet-mg e-mail group.

\section{Example of a successful query}

The following excerpt from the Sanet$\mathrm{mg}$ archives illustrates the combined use of the mail group and the database of SAREfunded research projects to answer a practical question quickly. As is common in e-mail exchanges, Nick Stone's original message (indicated by double-ticks, >>) is embedded in Kevin Gamble's reply (indicated by single ticks, >):

> From: kgamble@twosocks.ces.ncsu. edu (Kevin G amble)

$>$ Posted-Date: Wed, 22 Sep 1993 14:20:45 -0400 (E DT)

$>$ M essage-Id: <9309221820.AA-

14387@twosocks.ces.ncsu.edu>

$>$ Subject: Re: Pumpkins

$>$ T o: nick@vt.edu (N ick Stone)

> Date: Wed, 22 Sep 1993 14:20:45

-0400 (EDT)

$>$ C c: sanet-mg@ces.ncsu.edu

$>$ In-R eply-T 0: <9309221741.AA03951@wolf.ces.ncsu.edu> from “N ick Stone" at Sep 22, 93 01:41:10 pm

$>X$-M ailer: E LM [version 2.4 PL 22]

$>$ M ime-Version: 1.0

$>$ C ontent-Type: text/ plain; charset

$=$ U S-ASCII

$>$ C ontent-T ransfer-E ncoding: 7 bit

$>$ C ontent-L ength: 9369

$>$ SAN eters:
> I was expounding on the merits of the internet today to a colleague, an extension specialist, who does not use computers. $\mathrm{H}$ e challenged me with the following: "C an it tell me how to grow no-till pumpkins in eastern Virginia?" After determining that, in fact, he has a genuine need for this information, I said I would post the question. $C$ an anyone help? - I t may win a convert to information technology.

$>\mathrm{N}$ ever one to pass up a challenge I did a search of theSARE projects database at NCSU. The search turned-up the following on no-till pumpkins. Where it doesn't necessarily address Virginia, the document certainly could direct your colleague to a reliable source of information.

$>$ I haven't tried searching the other large agricultural databases, but I'm sure we can uncover some additional information.

$>$ H ow's this for speed? I'm returning this message within minutes of the original query. edu)

> K evin G amble (kgamble@ces.ncsu.

> LNE 89-19: REDUCED TILLAGE:ALTERNATIVE CROPPING SYSTEMS FOR VEGETABLE PRODUCTION IN THE NORTHEAST

(R evised 1/ 14/ 91)

$M$ ajor Participants:

Cornell U niversity: Robin R. Bellinder (Project C oordinator), research/ extension, D ept. of Vegetable C rops, I thaca, NY 14853. Weed Science, overall project coordinator, responsible for the weed control and tillage aspects of the projects in $\mathrm{N}$ ew York State, collaborator with the M ichigan project.

[ $N$ ote: List of other participants and contact information edited out by J. Auburn]

O verview

We are proposing to investigate the use of reduced and strip-tillage with

T able 2. U sefulness of various resources as rated by survey respondents.

\begin{tabular}{lcccr}
\hline & \multicolumn{2}{c}{ U sefulness rating $^{2}$} & \multicolumn{2}{c}{ Responses (no.) } \\
\cline { 2 - 5 } R esource & Mean & Median & 1-10 & Never tried \\
\hline E mail to/ from individuals & 9.4 & 10 & 59 & 2 \\
Sanet-mg mail group & 7.3 & 7 & 57 & $1^{y}$ \\
Other mail groups & 6.5 & 7 & 53 & 3 \\
World Wide Web & 7.1 & 7 & 36 & 20 \\
Gopher & 6.3 & 6 & 31 & 17 \\
Other on-line resource & 7.1 & 7 & 21 & 23
\end{tabular}

ZR atingswer emadeon a scale of 1-10 (where $1=$ not useful and $10=$ extremelyuseful) or never tried. M ean and median ratingsarecalculated from thosewho responded 1 to 10.

IT heone"never tried" for Sanet-mg (thesourceof thesurvey) isfrom a respondent whostated hereadsSanet-mg via itsU senet mi rror (alt.sustainable.agriculture) and thus technically does not use the mail group.

xR esources mentioned by respondents under "Other" in (a) included ftp, telnet, U senet, and library databases. 
interrow cover crops for vegetable production in thenortheast. The research will be conducted at research facilities and growers' fields in upstate $\mathrm{N}$ ew York and on L ong I sland, and in Connecticut.

We will evaluate different grass and legumemulch/ cover crop speciesfor their ability to suppress weeds, conserve soil moisture and control soil erosion. Crop performance in each of the mulch systems will bedetermined and herbiciderates will be reduced utilizing the weed-suppressing potential of the mulches.

The studies will be conducted on a wide range of crops that are grown throughout the northeast and north central regions of the US. We will include tomatoes, cabbage or cauliflower, snap beans, sweet corn and pumpkins at multiplelocations. The proposed research will help to define the specific requirements for reduced-tillage vegetable production that will be necessary if growers are to consider using such systems. Formulation of such recommendations in combination with the extension and education efforts involved in this project should provide commercial interest and participation in a system with both economic and environmental advantages.

Stone said that he received additional replies to his message, several of which were direct replies to him that did not appear in the Sanet-mg archives. He sent the colleague who raised the question a package of information that same afternoon. The colleague admitted to being impressed and stimulated to rethink his skepticism about this new technology, although nearly 2 years later, he still gets his e-mail through a secretary (personal communication with $\mathrm{N}$. Stone).

It was undoubtedly a factor that the person providing thisreply ( $G$ amble) ishighly familiar with SAN 's databases, since he is the person responsible for providing them on the Internet. In other cases, individuals from other universities and the $\mathrm{N}$ ational Agricultural L ibrary haveposted theresults of searches of Agricola and other databases in their replies to Sanet-mg queries.

\section{Survey of Sanet-mg subscribers}

To collect broader data on sustainable agriculture professionals' experiences on the Internet, I posted a survey to the Sanet-mg mail group in Summer 1995. Sixty-three responses were returned. The average respondent had subscribed to Sanet-mg for a little more than 1 year (mean: 16 months; median: 13 months), although several respondents had subscribed since the beginning of the mail group (September 1991). The average respondent had been using the Internet only 2 years (median response) to 2.5 years (mean response). M ost respondents were with land-grant universities and/ or cooperative extension or other public sectors, while a few respondents were farmers or ranchers or other private-sector participants. (T able 1).

On a scale of 1 (not useful) to 10 (extremely useful), respondents rated electronic mail to/ from individuals as highly useful (average ratings of 9-10), and other resources (Sanet-mg mail group, other mail groups, WWW) as quite useful (average ratings of 6 7, T able 2). Gopher was rated slightly lower, but several respondents commented that it was useful for specific resources that were not on the Web and also that it was easier to access when theW eb was inaccessible or slow due to heavy use. About one-third of the respondents replied that they had never tried the Web or Gopher, and only half of the respondents rated these resources at all, whereas nearly all respondents rated e-mail and mail groups.

$\mathrm{H}$ alf of the survey respondents said that they had asked one or more questions of Sanet-mg in the past 12 months (Table 3). Three-fourths of respondentshad sent oneor more replies in response to another's query, although several respondents noted that their replies may have gone to individuals rather than to the entire mail group. When asked if they passed information from Sanet-mg on to othersoutside of themail group in the past 12 months, nearly all (98\%) of respondents said that they had. The number of times they did so is highly negatively skewed (mean 52, median 10), as is the total number of people reached by such passing-on as estimated per respondents (mean 28, median 8). In other words, the most typical user (median) did so 10 timesa year to 8 other people, but a smaller number of more active users
2.7

7.9

5.9

4.6

4.8
O ffer an opinion

O ther
46

12

more active users 
raised the average frequency (as measured by the arithmetic mean) to weekly, each reaching 28 others on average. Comments volunteered by respondents indicated that information is passed on by e-mail to other I nternet users (individuals, local interest groups, and cross-postingsto other mail groups), and al so by print to non-I nternet users, including departmental newsletters and regional/ local calendars of events and individuals.

O f the 63 survey respondents, 34 replied to the questions about results of their most recently posted query. They reported receiving from 2 to 36 repliesto thequestion (mean 9.0, median 7), with an overall usefulness rating averaging 7.4 on a scale of 1 to $10(10$ $=$ extremely useful). $\mathrm{M}$ ost respondents (86\%) attempted to answer their questions via colleagues or printed and electronic information sources before they resorted to a posting to Sanet-mg. Electronic sources (colleagues by e-mail and Internet databases) were used about half as often as more traditional (in person, telephone, and print) sources (Table 4). To pics of questions posted included production techniques for crops and livestock; community development; food, nutrition, consumer and human health; policy and governmental affairs; education; economics; and many other topics.

\section{Conclusions}

The 63 respondents to the survey represent only $9 \%$ of the Sanet-mg subscribers, a very low response rate for a mail or telephone survey (Salant and Dillman, 1994). Low return rates are common to other surveys conducted by e-mail, however (MIDS, 1995; Perry, 1995). The danger of a low response rate is that respondents may be different from nonrespondents. In this case, it is likely that respondents to the survey are more active discussion participants and more likely to post answers (and probably queries, too) to mail groups. Thus, thefrequencieswith which they report posting messages to Sanet-mg are probably higher than the group as a whole. The participants in Sanet-mg generally, and the survey respondentsin particular, arelikely to be early adopters rather than representative of the broad population of agricultural professionals working in sustainable agricul- ture, or in agriculture generally. Furthermore, one would expect the participants in Sanet-mg (or any mail group) to view the group relatively positively, since dissatisfied participants would likely unsubscribe. Accordingly, conclusionsfrom thissurvey should be interpreted as applicable to these selfselected early adopters rather than to the larger audience of all agricultural professionals.

The survey results show that, among these early adopters, use of the more complex Internet tools and functions is less common than e-mail, and also that the sources more likely to beconsulted beforeturning to e-mail arethemoretraditional (in-person, telephone, and print) rather than Internet services such as Gopher and WWW. This situation may change as more information becomes available via these services, and the tools for accessing information become more effective. Becoming familiar with the databases available, and learning to use them effectively, probably will require considerable investment by the user. E ven librarians, who are trained as information searchers, rate their own Internet searching skills as inadequate, due to lack of time and resources (Basu, 1995).

Individuals active in sustainable agriculture may be more predisposed than other agricultural professionals to use and value the Internet for the following reasons. E-mail groups and other Internet discussions are participatory and democratic by nature, with limited distinction made between expertsand nonexperts. This I nternet culture is consistent with the participatory approach to research and extension (Gerber, 1992) that is common within sustainableagriculture. Farmers and ranchers are viewed by many in sustainable agriculture as experts in their own right, although their expertise arises from practical experiencerather than scientific training. The expertise of farmers and ranchers is different from, but complementary to, the knowledge of university experts. The relatively low representation of farmersand ranchers in the Sanet-mg mail group, however, leaves the participatory potential of the Internet relatively unexploited. In the future, improved access in remote rural areas, better

T able 4. Percentage of respondents who reported consulting various sources for an answer before querying Sanet-mg (out of the 33 who had posted a query in the past 12 months).

\begin{tabular}{llll}
\hline Source consulted & Yes & No & No answer \\
\hline Colleague(s) in person or by telephone & 67 & 30 & 3 \\
Colleague(s) by email & 30 & 67 & 3 \\
Reference book(s)/ printed information & 55 & 42 & 3 \\
Database/ on-line resource via Internet & 30 & 64 & 33 \\
Other sources & 12 & 55 \\
\hline
\end{tabular}


software, more training, and richer bodies of information may be needed to attract more farmers and ranchers to participate.

A widely publicized example of Pagell's (1995) concerns about the difficulty of judging the quality of information posted to the Internet is the controversy over O ncoL ink, a WWW-based cancer information servicebased at the U niv. of Pennsylvania (H oke, 1995). Agricultural professionals may find similaritiesin some of $\mathrm{H}$ oke' squotes from physicians who feel a responsibility to restrict the availability of non-peer-reviewed information to the public. On the other hand, many sustainableagricultureactivistsmay sympathize with those quoted by $\mathrm{H}$ oke who feel that "peer review serves to perpetuatethestatusquo...in an area in which medical expertshavefailed to provide adequate solutions."

A nother characteristic of the Internet lends itself to sustainable agriculture discussions: despitethefact that sustainableagriculture is a broad concept that is applicable across a wide range of disciplines and cropping systems, research and education professionals concentrating in sustainable agriculture have been, until recently, fairly few. As a result, there has been a strong tendency to interact with distant colleagues and to adapt locally information that is drawn originally from geographically diverse experiences. In the words of one survey respondent, "... this movement consists of a web of people scattered to the winds. M ost of us are working on shoestring budgets, and getting together in real time tends to be reserved for those with solid institutional connectionsand budgets. I don't know how I'd keep up with what others are doing without some kind of Internet access." C ountering the need for this collegial interaction is the real concern for e-mail overload commented upon by several survey respondents, particularly those without sophisticated e-mail software that filters incoming messages from mail groups away from higher-priority, personal e-mail messages. I ndeed, the two participants in the successful query example cited above, have stopped subscribing to Sanet-mg and participate only by reading its archives on the $U$ senet newsgroup alt. sustainable.agriculture $(\mathrm{N}$. Stone and K. Gamble, personal communication). U sing U senet, and filtering incoming group messages to a secondary mailbox that isread when time is available, both are appropriate responses to reducing the e-mail overload inherent in mail groups. $N$ onetheless it is unlikely that $\mathrm{G}$ amble would have replied to Stone's query within minutes of the original query if it had not appeared in his incoming mailbox.

Pressures from increasing subscription prices, declining budgets, increasing volume of information, and increasing delays may be forcing scientific publishing toward electronic dissemination (Clement, 1994), agriculture being no exception. Concerns about lack of formal peer review in I nternet-based journals by the medical community (Kleiner, 1995) will have to be addressed by the agricultural community. D espiteconcernsabout thequality of information, overloaded e-mail in-boxes, and the training needed to use Internet resources effectively, a substantial number of agricultural professionals today are finding the I nternet a useful adjunct to, although not a replacement for, more traditional tools in their efforts to answer practical questions.

\section{Literature Cited}

A uburn, J.S. and J.T. MacLean. 1993. D evelopment of an information network for sustainable agriculture. J. Agr. Food Info. 1(3):25-40.

Basu, G. 1995. U sing I nternet for reference: myths vs. realities. Computers in Libraries 15(2):38-40.

Clement, G. 1994. Evolution of a species: science journals published on the Internet. Database 17(5):44-52.

Crawford, W. 1995. Estimating internet traffic. D atabase 18(1):6.

Dennett, S. 1994. Let's stop hyping the Internet and start building a better I way. InfoWorld 16(47):62.

D ouglass, Gordon K. 1984. The meanings of agricultural sustainability. In: G.K. D ouglass (ed.). Agricultural sustainability in a changing world order. Westview Press, Boulder, Colo.

Finn, R. 1995. Superhighway or supercollider? Finding useful I nternet information. TheScientist 9(7):17-18.

Fretz, T.A ., D.R. K eeney, and S.B. Sterrett. 1993. Sustainability: defining the new paradigm. H ortT echnology 3:118-126.

Gerber, J.M . 1992. Participatory research and education: science in service to horticultural producers. H ortT echnology 2:12-15.

Gips, Terry 1988. What is sustainable agriculture? In: P. Allen and D. Van Dusen (eds.). Global perspectives in agroecology and sustainable agricultural systems. Proc. 6th Intl. Sci. Conf. Intl. Fed. O rganic Agr. M ovements, Agroecology Program, U niv. Calif., Santa Cruz.

H arwood, Richard R. 1990. A history of sustainable agriculture, p. 3-19 I n: C.A. Edwards, R. Lal, P. M adden, R.H. Miller, and G. H ouse (eds.). Sustainable agricultural systems. Soil Water Cons. Soc., Ankeny, lowa.

H oke, F. 1995. Struggle over online cancer service spurs larger medical ethics debate. The Scientist 9(7):1,6-7.

Jennings, R. 1995. Who needs the Internet. Byte 20(1):296. 
K eeney, Dennis. 1990. Sustainable agriculture: definition and concepts. J. Prod. Agr. 3(3):281285.

K leiner, K . 1995. Internet journals not quite what the doctor ordered. N ew Scientist 147(1984):6.

Landauer, T.K . 1995. The trouble with computers. The M IT Press, Cambridge, M ass.

M atrix I nformation and D irectory Services. 1995. Summary of the results, second TIC/ M ID SI nternet demographic survey. M atrix $N$ ews 5(4):1-10.

N ulty, P. 1995. Why you can-and should-wait to get on the Internet. Fortune 131(12):148.

Pagell, R .A . 1995. Q uality and the Internet-An open letter. Online 19(4)7-9.

Perry, C. 1995. T ravelers on the Internet-A survey of I nternet users. O nline 19(2):29-33.

R othke, B. 1994. Don't pet the Internet. D atamation 40(11):92.

Quarterman, J.S. and G. Phillips 1993. Internet growth. M atrix N ews 3(12):

Salant, P. and D.A. Dillman. 1994. H ow to conduct your own survey. Wiley, N ew York.
Stoll, C. 1995. Silicon snake oil: second thoughts on the information highway. Doubleday, N ew York.

Sustainable A griculture N etwork. 1992. M anaging cover crops profitably. Sustainable Agriculture Research and Education Program, U niv. of Vermont, Burlington.

SustainableA griculture N etwork. 1993a. Sustainable agriculture directory of expertise. Sustainable Agr. Res. and Edu. Program, U niv. of Vermont, Burlington. (revised edition available in electronic form only, O ctober 1994)

SustainableA gricultureN etwork. 1993b. The O ctober 1993 revised project summaries from the U SD A SARE program and the EPA-U SD A ACE program. Available on diskette from $U$ tah State U niv. or via gopher to gopher.ces.ncsu.edu (not published in print).

SustainableA gricultureN etwork. 1994. Showcase of sustainable agriculture information and educational materials. Sustainable Agr. Res. and Edu. Program, U niv. of Vermont, Burlington.

van K irk, D. 1994. U nraveling the Internet hype. InfoW orld 16(52-1):52.

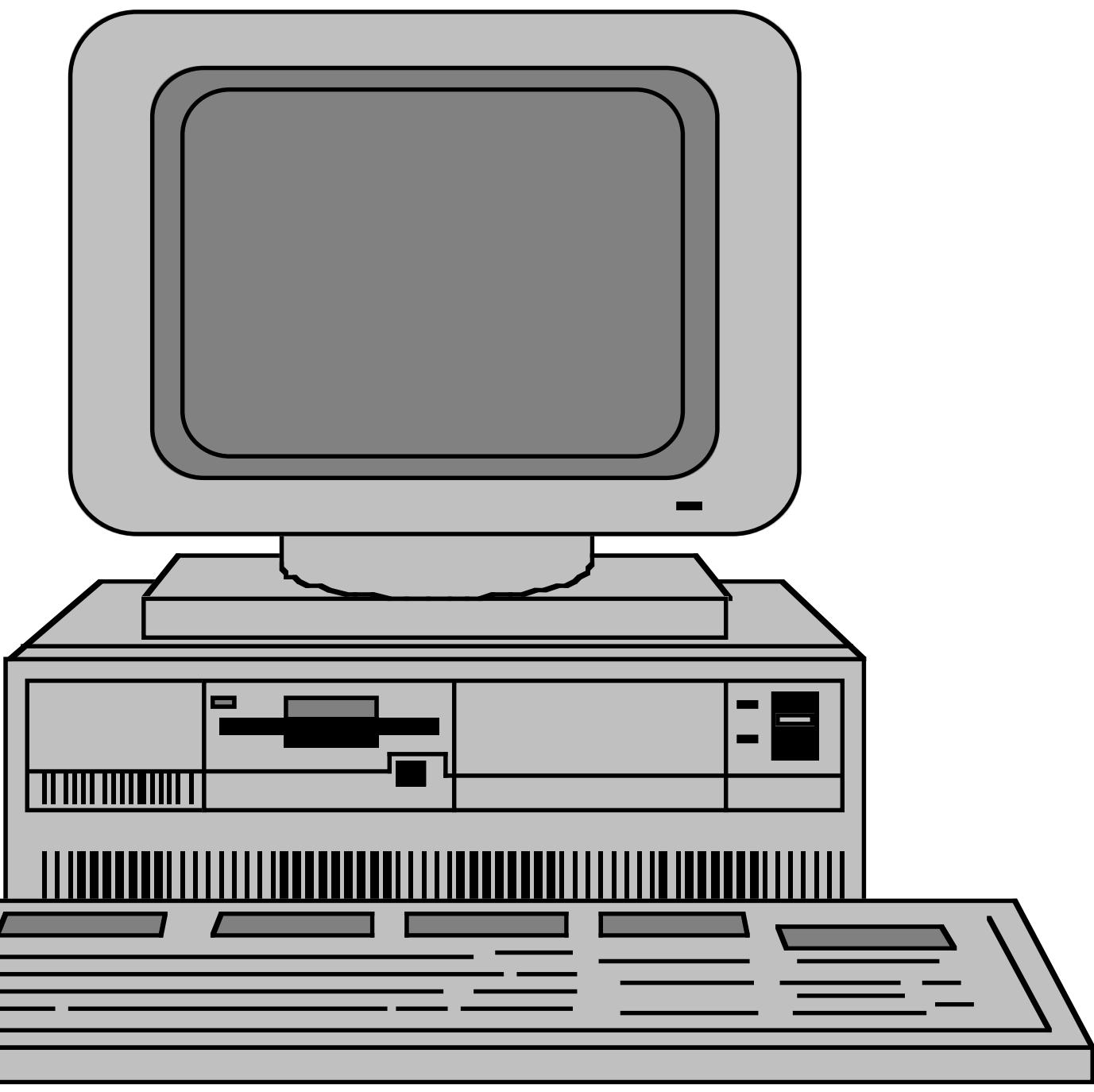

